\title{
Performance of Micro and Small Enterprisers in Tigray, Northern Ethiopia
}

Gebretsadik Gebru Wubet ${ }^{1 *}$ and Gagoitseope Mmopelwa ${ }^{2}$

${ }^{1}$ Department of Statistics, College of Natural and Computational Sciences, P.O. Box 231, Mekelle University, Mekelle, Ethiopia (*gebretsadik.gebru@ mu.edu.et)

${ }^{2}$ Department of Environmental Sciences, University of Botswana, Gaborone, Botswana.

\begin{abstract}
Micro and Small Enterprises (MSE) have become the focus of attention for the economic development, economic growth and job creations in the world. Majority of the firms worldwide are dominated by businesses of micro and small enterprises. In developing countries, the informal sector that mainly establishes MSE remains the major source of employment and income for the urban population. A study was conducted to examine the performance of MSE in three zones of Tigray State, namely, Southern zone, Mekelle zone and Eastern zone. The data was collected using structured questionnaire on $246 \mathrm{MSE}$ business owners. The data are analyzed using multiple linear regressions (dummy), Cross tabulations and chi-square test for test of independence. The result revealed that Gender, initial capital, enterprise and job type are found to be important factors of performance of MSE. There is a gender difference on sector type, education level and work sheds of micro and small enterprises business owner. The result also showed that initial capital has positively affected the performance of business owners and men headed business owners have better performance than female headed business owners.
\end{abstract}

Keywords: Micro- and Small Enterprises, Performance, Gender, Tigray, Ethiopia.

\section{INTRODUCTION}

Micro- and Small Enterprises (MSEs) have become the focus of attention for economic development, economic growth and job creations in the world. Majority of worldwide firms are dominated by businesses of micro and small enterprises. The importance of MSEs in the economies has been recognized by many organizations such as World Bank, United Nation (UN) Agency, governments, non-governmental organizations and private entities (Kenya Economic Survey, 2009).

Van Biesebroeck (2005) showed in his review of national surveys conducted in several African countries estimate that between $17 \%-27 \%$ of the working population was employed in MSEs, being nearly twice the employment of large scale enterprises and public sector. The United States Agency for International Development (USAID) considers that MSE employ a third or more of the labor force in low income countries (USAID, 2010). Wanambisi and Bwisa (2013) showed that the MSE sector employed around 2.3 million people and generates around 14\% of the Kenya's Gross Domestic Product (GDP). 
Research on MSEs has grown during the last decade. MSE's plays a significant role in the economy through innovation and employment creation. Consequently, the performance of an economy of a nation is closely associated with the performance of MSE business owners. Habtamu et al. (2013) have reported on their studies that MSEs do serve as a means of bringing economic transition by using the skill and the talent of people without requiring high-level training, much capital and sophisticated technology. This makes the sector more preferable to business entry, unemployment reduction, income generation, and poverty alleviation.

Ethiopia, with the fastest economic growth in Africa and scored double-digit growth in the past 10 consecutive years, is also one of the developing countries which have taken measures to enhance the operation of MSEs by considering their contributions. UNDP (2012) has indicated that the development of MSE's is the key component of Ethiopia's industrial policy direction that will contribute to the industrial development and economic transformation of the country. Even the country's latest grand plan (the "Growth and Transformation plan-GTP”, 2011-2015) has stressed the need for providing support to MSE and vital contribution of small sectors for industrial transformation.

Tigray has recognized and paid attention to the development of MSEs, because they are important vehicles to improve the challenges of unemployment, economic growth and equity within the region. Tigray Micro and Small Enterprises Agency (TMSEA) was established to assist MSE business owners by providing training, financial facilities, providing work and sell sheds, creating market linkages and some related things to the development and expansion of MSE. This development is expected to continue the industrial transformation by importing new experience, technologies and sharing with performance of MSE owners. Studies by Aregash (2005); and Gebreyesus (2009), conducted in this region have focused on the assessment of job creation and intervention of business development services (BDS). Nevertheless, they didn't address the driving factors for the performance of MSE business owners, Skills and capacity building acquires and gender difference of the performance of MSE's. Hence, this study mainly focused on examining the driving factors of the performance of MSE's business owners, and described the gender difference, the socioeconomic characteristics and skills and capacity buildings acquired from responsible bodies. 


\section{LITERATURE REVIEW}

There is no universally accepted definition of MSEs because the classification of business into micro, small and medium scale is a subjective judgment Ekpeyong and Nyong (1992). Egbuogu (2003) showed that definitions of MSEs vary both between the countries and between the continents. The major criteria used in the definitions according to Carpenter (2003) could include combinations of number of employees, financial strength, sales value, relative size, initial capital outlay and types of industry. In countries such as the United States of America, Britain and Canada, micro, small and medium business is defined in terms of annual turnover and number of paid employees. In Ethiopian context the improved definition of MSE is presented in table 1 below.

Table 1.Improved definition of MSE in Ethiopian context.

\begin{tabular}{|llll|}
\hline Level of the enterprise & Sector & Human power & Total asset \\
\hline Micro enterprise & Industry & $\leq 5$ & $\leq 100000(\$ 6000$ or $€ 4500)$ \\
\cline { 2 - 4 } & Service & $\leq 5$ & $\leq 50,000(\$ 3000$ or $€ 2200)$ \\
\hline \multirow{2}{*}{ Small enterprise } & Industry & $6-30$ & $\leq$ birr 1.5 million $(\$ 9000$ or $€ 70000)$ \\
\cline { 2 - 4 } & Service & $6-30$ & $\leq$ birr $500,000(\$ 30000$ or $€ 23000)$ \\
\hline
\end{tabular}

Sources: FDRE, 2011

\subsection{MSE Development and the Renaissance of Ethiopia}

MSE is one of the institutions given recognition in the country's industry development plan and is the fact that it serves as vehicle for economic growth of the country. Ethiopia has its own political reasons for giving priority to MSE development. The government is devoted to fulfill the benefits of the farmers as they are basis for developmental state in rural, and they are the bases for mobilizing community and bring about development and good governance. Therefore, MSE plays a great role in urban as entrepreneurs use their resource and labor intensive similar with the farmer in the rural.

Long time in history development and expansion of MSE, was widely considered as sign of backwardness (for example, previously due to cultural backwardness it was prohibited for males/female to work/employee on bar or restaurants) and lack of another alternative in all segments of the society and in the party /EPRDF/ too. However, it resulted from misunderstanding that MSE are basis for a number of developments in the technology sector of these days. Hence it 
is better to be noted that renaissance of the country would not be realized unless such false perceptions are changed and replaced with correct one.

Although there are various problems that hinder the development of MSE, the main problem is backward attitude towards rent seeking. Moreover, technology, skill, initial capital and market linkage challenges have their own role to lag the development. Although the problems can be revealed in various forms, perceiving the MSE themselves as reflection of poverty and backwardness, waiting government create jobs rather than being innovative, failure in developing the culture of saving and living with one's income/ dependency/ are some of the indicators of failure in improving productivity and being competent in market. Lack of access to sufficient seed money or finance facing huge capital problem at start up stage is another bottleneck, and it resulted from failure of having strong trust in ones saving effort with both the actors and families of actors. Lack of government and business owners' commitment towards changing the backward technology is another challenge of the MSE development. Lack of access to market for their products and services that are associated with failure in producing according to market in terms of quality and price, and competitive approach, is the other problem. Unable to solve one's problem by themself and absence of strong system of support that can help MSE's effort in solving their problems are other related problems.

Hidayet et al. (2010) on their empirical studies showed that MSE contribute to over 55\% of GDP and over 65\% of total employment in high-income countries. MSEs and informal enterprises, account for over $60 \%$ of GDP and over $70 \%$ of total employment in low-income countries, while they contribute over $95 \%$ of total employment and about 70\% of GDP in middleincome countries.

Alasadi and Abdelrahim (2007) studies showed that MSEs are considered as a vital component of the socioeconomic development of both developed and developing countries, usually some of these enterprises collapse within the first few years of their start-up. Of those operating, some grow rapidly, while others grow slowly. So, it is important to identify the factors that cause performance because it helps new entrants of the sector to consider these factors for future performance in business. These factors could vary from one country to another due to the economic, geographical and cultural differences. Some business owners are highly educated and extremely successful whereas others have yet to complete their high school but are equally successful. Nevertheless, education level can have an effect on the performance of a business as 
noted in many studies because education improves literacy, quantitative training, and social and communication skills.

Wanjohi and Mugure (2008) described that a business started by one person has a greater chance of failure than a firm started by more than one person. Thapa et al. (2008) also found on their studied that the education of owners has positive effect on entrepreneurial and small business performance. Similarly, Rose et al. (2006) in their study of the 'Dynamics of Entrepreneurs Success Factors', reported that, higher education level helps the business owners to have better knowledge and skills which contribute to the success of their venture. Another study by Charney and Libecap (2000) found that entrepreneurship education produces self-sufficient enterprising individuals. Furthermore, they found that entrepreneurship education increases the formation of new ventures, the likelihood of self-employment, the likelihood of developing new products, and the likelihood of self-employed graduates owning a high-technology business.

Entrepreneurs vary in age from young to old in many instances. An individual may begin a business as a hobby or secondary source of income and have it grow into a profit-driven enterprise. A number of studies have focused on the entrepreneurial characteristics of the owners/managers of small businesses as key factors to small business success. Age of the owners/managers was one of the most important characteristic that was repeatedly used to predict small business performance and success (Lussier and Pfeifer, 2001). Lussier (1995) reported on his studied that 'people without any college education who start a business have a greater chance of failing than people with one or more years of college education. His studies also showed that younger people who start a business have a greater chance to fail than older people starting a business. Similarly, Praag (2003), in his study of business survival and success of young small business owners, found that younger small business starters have a lower success and survival probabilities than older starters. The chance of both voluntarily and forced exit from the business is higher to young starters. From these studies, one can understand that the age of small business owners have its own contribution to the success and failure because individuals learn not only from formal education but also from their walks of life.

Alasadi and Abdelrahim (2007) in their study of small business performance in Syria showed that as the age of the business owner increases it contributes to the success of the enterprises performance of the business owners. And they argued also that increased age brings 
with it a sufficient level of accumulated knowledge or experience of a certain trade to try going into self-employment alone.

Understanding the level of respondents ${ }^{\text {ee }}$ education helps in identifying and determining the development approaches to be followed. High level of human capital and research and development are positively associated with the performance of firms. They promote the growth of firms from low level of activities to large and better performance of enterprises (Aklilu, 2010). According to Bereket (2010) most of the MSE owners (45.5\%) use their profit to create new business while the study of Selamawit (2015) has showed that 26\% of the entrepreneurs involved on trade sectors.

\subsection{Gender Dynamic of MSE}

Women entrepreneurs around the world are now making a difference in the sector of entrepreneurship. In most countries, the majority of MSEs are owned and operated by women. Furthermore, since working proprietors are the single largest category of the labor force, the great majority of the workers are also women. MSEs headed by women tend to be concentrated in a relatively narrow range of activities: beer brewing, knitting, dressmaking, crocheting, cane work, and retail trading. MSE's headed by women are more likely than their male counterparts to operate from the home. Since it is the home-based MSEs that tend to be overlooked, women owners of MSEs are particularly likely to be the "invisible entrepreneurs" (Mead and Liedholm, 1998).

Lack of access to credit/ finance is almost universally indicated as a key problem for MSE entrepreneurs. Accessing credit, particularly for starting an enterprise, is one of the major constraints faced by women entrepreneurs. Women often have fewer opportunities than men to gain access to credit for various reasons, including lack of collateral, an unwillingness to accept household assets as collateral and negative perceptions of female entrepreneurs by loan officers (Mahbub, 2001). According to Lussier (1995), businesses that start undercapitalized have a greater chance of failure than firms that start with adequate capital.

According to Bereket (2010) the majority's education levels of all the entrepreneurs are from grade 9-12 (36.1\%). Next to grade 9-12, the respondents with diploma level of education and first degree holders ${ }^{\text {ee }}$ accounts for $18.5 \%$ and $8.3 \%$ of the sample respondents respectively. However, it is only recently that women's entrepreneurship has gained the attention of economic planners and policy makers. 
According to Aregash (2005); and Amha and Admassie (2004), 98\% of business firms in Ethiopia are micro and small enterprises, out of which small enterprises represent $65 \%$ of all businesses. More than half of all women entrepreneurs in Ethiopia often face gender related challenges related to establishing new businesses as well as operating or expanding existing businesses. Women are disadvantaged due to culture, religion and tradition. For instance many women face difficulty in raising credit finance from banks as well as borrowing via informal networking.

Walker and Brown (2004) have reported that MSE's performance can be measured by financial and non-financial criteria although the former has been given most attention in the literature. Traditional measures of business success have been based on either employee numbers or financial performance, such as profit, turnover or return on investment. For businesses to be deemed successful or well performed these financial measurements require increases in profit. As cited from the studies of Walker and Brown (2004); and Hall and Fulshaw (1993), 'the most obvious measures of performance are profitability and growth'. In economic terms this is seen as profit maximization. Economic measures of performance have generally been popular due to the ease with which they can be administered and applied since they are very much hard measures. In this study, performance of MSEs is measured by yearly profit since it is better than the nonfinancial measures in terms of reducing the subjectivity of the measurement results. Non-financial factors have also their own contribution for higher profit and growth for the business owners, but, to reduce subjective measurement only financial profit considered in this study.

\section{METHODOLOGY}

\subsection{Description of the Study Area}

This study was conducted in three zones of Tigray Regional State, northern Ethiopia located at $38^{0}$ 48'30" and $39^{\circ} 49^{\prime} 0^{\prime \prime}$ longitude easting and $12^{\circ} 51^{\prime} 0^{\prime \prime}$ and $13^{\circ} 51^{\prime} 30^{\prime \prime}$ latitude northing. The maximum and minimum elevation value above the sea level of the study area is 3910 and 76 (m.a.s.l). This region shares common borders with Eritrea in the north, the State of Afar Region State in the east, the State of Amhara Region State in the south, and the Republic of the Sudan in the west. Excluding Mekelle town, the State capital, there are five administrative zones, namely eastern, northern, central, western and northwestern zones. Tigray Region is called Region 1 according to Ethiopian Federal Constitution which is $787 \mathrm{~km}$ far from Addis Ababa and home land 
of the Tigrayans, Irob and Kunama peoples. Its capital city is Mekelle with an estimated area $50,078.64 \mathrm{~km}^{2}$ and has an estimated population 6.96 million, of which $18.8 \%$ live in urban (CSA, 2015). The study area covers all MSEs of the selected zones of Tigray region. From the total population, $49.2 \%$ are males and $50.8 \%$ are females, of which $80.5 \%$ live in rural areas depending on farming teff, wheat, corn sorghum, barley Niger seed etc. and on irrigation (CSA, 2015). The economic active age group accounts for about $51.85 \%$ of the total population and $95.5 \%$ of the total population are orthodox Christians.

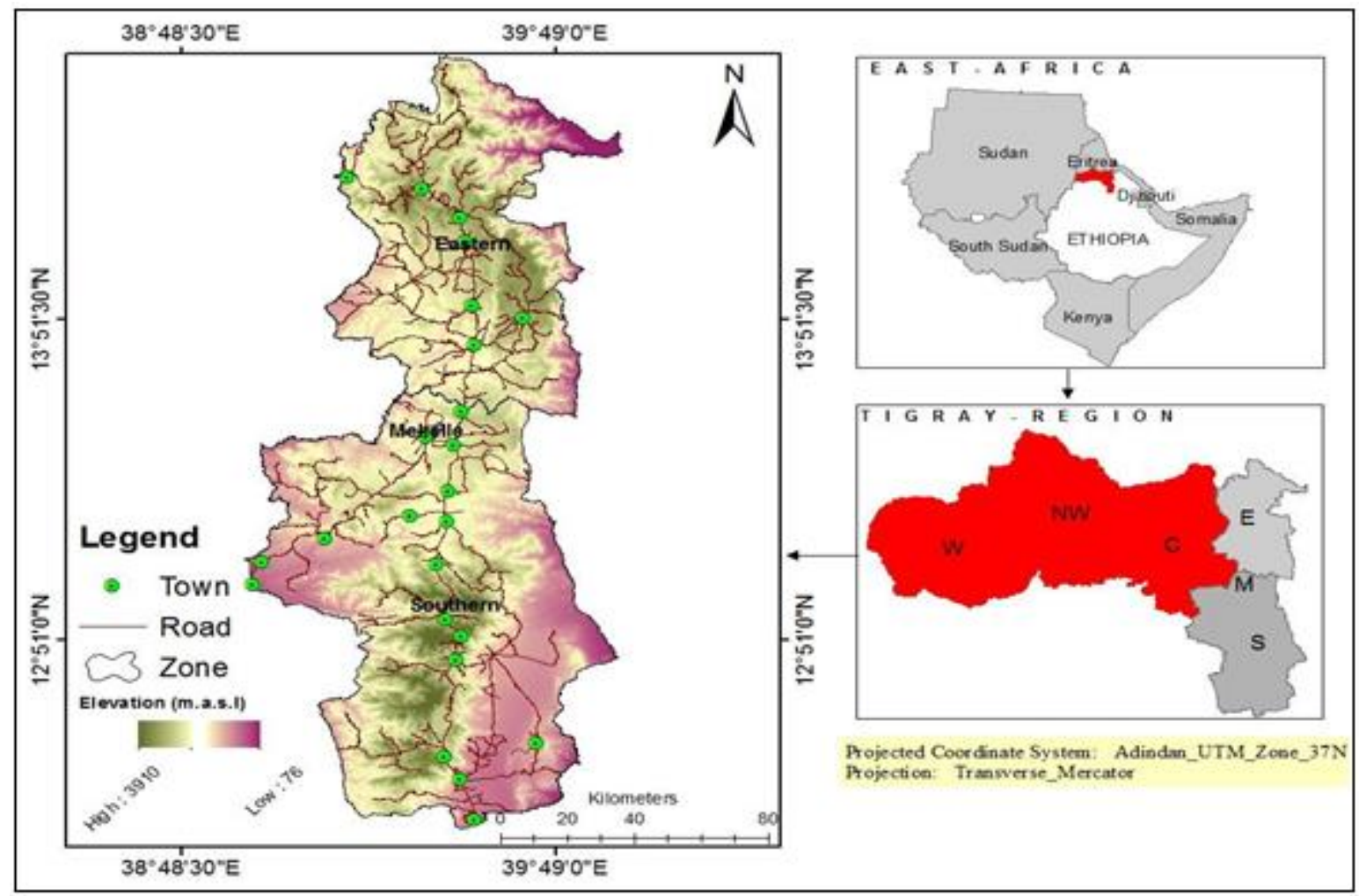

Figure 1. Location of the study areas.

\subsection{Poverty, Unemployment and Physical Aspects of the Region}

According to the report by the Ministry of Finance and Economic Development of Ethiopia $2014 \backslash 15$, the poverty rate of the region (citizens whose daily income is less than one dollar a day) was $22.5 \%$ (MoFED, 2015). However, in the year's 2016\17, the poverty rate is believed to be lower than it was in the 2014l15 due to the integrated efforts made in the household based package in the rural areas and due to the trainings and credits given to the MSEs in the urban areas. According to CSA (2015), unemployment rate in the urban areas of the Tigray Regional State in the year 2003 was $28.8 \%$ of which $20.6 \%$ were males and $36.2 \%$ were females but this 
unemployment rate has decreased to $19.0 \%$, (11.2\% males and $16.2 \%$ females $)$ in the year 2009 . This achievement was due to the integrated effort made by government, private sectors and other development partners.

The landform is complex composed of highlands (in the range of 2300 to 3200 meters above sea level) and lowland plains (with an altitude in the range 500 to 1500 meters above sea level). It has diversified agro-ecological zones and niches each with distinct soil, geology, vegetation cover and other natural resources (Araya et al., 2010; Gebrehiwot and van der Veen, 2013). Thus, this area was also partly chosen for this study because of unemployment rate is high in this region than the other regions of Ethiopia. And the three zones was chosen purposively as those are potential in performance of MSEs

\subsection{Research Design and Data Collection}

In this study a cross sectional research design was employed to assess the factors that affect the performance of entrepreneurs of Tigray region. The reason for using this research design is that it enables the researcher to examine the relationship between different variables like gender dynamics, sector dynamics and different socioeconomic characteristics. This study is both qualitative and quantitative research that attempts to accumulate existing information and data regarding evaluating MSE performance of the business owners. The quantitative aspect of the studies are age, total number of households, yearly profit, and the qualitative aspect of the study are gender, sector types, job types, education level, work sheds and types of enterprises. It is appropriate to use this method in order to verify the observations regarding the intended research questions.

The qualitative aspects include personal interviews and observations of the business owners. The study employed both primary and secondary sources of data collection. In order to realize the target, the study has used well-designed structured questionnaire. The required data has been collected from the owner of the MSEs. The layout of the questionnaire has been kept very simple to encourage meaningful participation by the respondents. The relevant secondary data has been collected from files, pamphlets, office manuals, circulars and policy papers from the MSE's Regional Office.

\subsection{Sampling Techniques and Procedures}

Three zones are chosen among six for this study i.e. southern, Mekelle, and eastern zones because MSEs performance in these zones is better compared to others. In Tigray, there are around 117,234 
MSE owners of which $49.87 \%$ are female owners, and the coverage of micro and small enterprises are $80.3 \%$ and $19.7 \%$, respectively (see Table 2). Simple random sampling has been used to get information from the MSEs of the three zones.

Table 2. Types of sectors with number of MSE owners of Tigray region (Source: FDRE, 2011).

\begin{tabular}{|lll|}
\hline Type of sectors & Number of MSE owners & Percent \\
\hline Manufacturing & 15,716 & 13.5 \\
\hline Construction & 5,622 & 5 \\
\hline Urban agriculture & 22,999 & 20 \\
\hline Services & 29,003 & 25 \\
\hline Trade & 43,894 & 36.5 \\
\hline Total & 117,234 & 100 \\
\hline
\end{tabular}

Two stage sampling technique was adopted in this study. First, purposive sampling technique used to select three zones from six zones of Tigray region, followed by simple random sampling from each zone. Sample size was determined from the following formula as suggested by Cochran (1963).

$$
n=\frac{n_{0}}{1+\frac{n_{0}-1}{N}}, \quad \mathrm{n}_{0}=\frac{\mathrm{z}_{\alpha / 2}^{2} \mathrm{pq}}{\mathrm{d}^{2}} n_{0}=\frac{z_{\alpha / 2}^{2} p q}{d^{2}}
$$

Where, $\mathrm{n}$ is the required sample size,

$\mathrm{Z}$ is value for the selected alpha level, 1.96 for (0.25 in each tail) $95 \%$ confidence level,

$\mathrm{p}$ is the estimated proportion of an attribute that is present in the population, and

$\mathrm{d}$ is the acceptable margin of error for proportion being estimated.

By using the above parameters as $\mathrm{p}=0.2$ and $\mathrm{d}=0.05$, the sample size in this study was estimated to be 246 samples of MSE and presented below (Table 3) the proportion of the sample from each zone.

Table 3.Sample size allocation from the three zones.

\begin{tabular}{|lll|}
\hline Zones (strata) & Population & Proportionate Sample \\
\hline Mekelle & 12538 & 114 \\
\hline South eastern & 3711 & 34 \\
\hline Eastern & 10825 & 98 \\
\hline Total & 27074 & 246 \\
\hline
\end{tabular}




\subsection{Methods of Data Analysis and Processing}

This study used both descriptive and inferential statistical methods of data analysis. The descriptive statistical method describes the socioeconomic characteristic using tables and graphs and the inferential statistical method inferred for the target population using chi-square test of independence and multiple regression analysis. The reason why chis-square test was used is that to see the association between variables, like sector types and gender dynamics.

\subsubsection{Chi Square Test of Independence}

The chi square test of independence compares two categorical variables in a contingency table to see if they are related. The hypothesis test is:

$\mathrm{H}_{\mathrm{o}}$ : The two variables ( rows and columns) are independent

$\mathrm{H}_{1}$ : The two variables are correlated.

Reject the null hypothesis if the p-value is less than $5 \%$. The chi square statistic value is computed as follows:

$$
X_{d f}^{2}=\sum \frac{\left(O_{i}-E_{i}\right)^{2}}{E_{i}}
$$

Where, df is the degree of freedom; $\mathrm{O}_{\mathrm{i}}$ is the observed value; and $\mathrm{E}_{\mathrm{i}}$ is Expected value.

\subsubsection{Multiple Regressions}

The multiple regression model is as follows:

Yearly profit

$$
\begin{aligned}
& =\beta_{0}+D_{1} \text { male }+\beta_{1} \text { age }+\beta_{2} \text { hhsize }+D_{2} \text { givenworkplace } \\
& +\beta_{3} \text { initialcapital }+D_{4} \text { smallEnterprise }+D_{5} \text { literacy }+D_{6} \text { Jointwork }+\mu
\end{aligned}
$$

\section{RESULTS AND DISCUSSION}

\subsection{Respondents Demographic Profile}

Table 4 shows that about $51 \%$ of the respondents were male headed and $49 \%$ female headed entrepreneurs and this result is similar with Selamawit (2015) study on gender classification of the enterprises case of Mekelle town. Bultum (2017) also studied the performance of MSE's case of Adama and showed that the majority of the sampled households were dominated by male headed entrepreneurs. This result of this study shows that the average age of the entrepreneurs' are 40 years old and the average total household size was 3.9. Majority of the entrepreneurs education 
levels are first cycle (32.3\%) and high School (24.5\%). People without any college education who start business have less performance than peoples with one or more years of college education. Of course, younger business owners less perform than older business owner.

Table 4. Respondents Demographic Profile.

\begin{tabular}{|llll|}
\hline Descriptive & \multicolumn{2}{c|}{ Gender } & Total \\
\cline { 2 - 3 } & Female & Male & \\
\hline Number of entrepreneurs & $120(48.9 \%)$ & $126(51.1 \%)$ & 245 \\
\hline Average age & 36.27 & 42.42 & 39.39 \\
\hline St. Deviation (age) & 10.31 & 13.93 & 12.67 \\
\hline Average house hold size & 3.99 & 4.34 & 3.9 \\
\hline St. deviation house hold size & 1.94 & 2.41 & 1.85 \\
\hline Education level & & & \\
\hline Illiterate & $22(9 \%)$ & $15(6 \%)$ & $37(15 \%)$ \\
\hline First cycle(1-6) & $33(13.5 \%)$ & $46(18.8 \%)$ & $79(32.3 \%)$ \\
\hline Second cycle(7-8) & $21(8.6 \%)$ & $19(7.8 \%)$ & $40(16.4 \%)$ \\
\hline High school (9-12) & $39(16 \%)$ & $21(8.5 \%)$ & $60(24.5 \%)$ \\
\hline Certificate or diploma & $3(1 \%)$ & $13(5.5 \%)$ & $16(6.5 \%)$ \\
\hline Degree and above & $2(0.8 \%)$ & $11(4.5 \%)$ & $13(5.3 \%)$ \\
\hline Total & $120(48.9 \%)$ & $125(51.1 \%)$ & $245(100 \%)$ \\
\hline
\end{tabular}

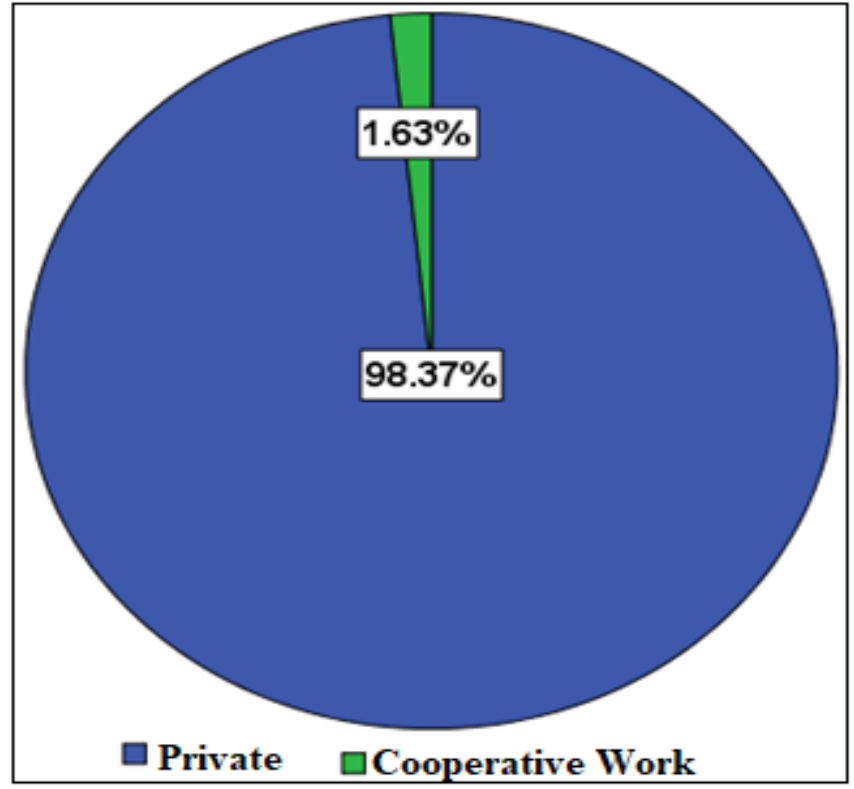

Figure 2. Type of work involved in MSEs.

Results reveal that almost all of the entrepreneurs' (98.37\%) business is run by one person (private), while only $1.63 \%$ entrepreneurs have their businesses run jointly (with partner or cooperative work) (Fig 2). This is because when entrepreneurs start work with partners or with (C) CNCS, Mekelle University 
more than two people there is lack of trust among the partner. In a discussion among partner, everyone tries to impose their ideas upon the others which lead to conflict of ideas. Ultimately the group disintegrates in a belief that they will be successful if they stand by their own. Therefore, to avoid such inconvenience entrepreneurs prefer to work independently or privately for better performance of their business. However, Wanjohi and Mugure (2008), reported that a business started by one person has a greater chance of failure than a business started by more than one person and this assertion is contrary to the above result. This is because people working in MSE in Ethiopia particularly in Tigray region has less experience and education level, as the MSE business is at the infant stage. For better performance of individuals and growth economy of the country business run by partners are powerful.

According to table 5, to improve their profit the entrepreneurs expand their existing sector type or changes to another sector type in their future plan. The result revealed that $35.8 \%$ of entrepreneurs' long run plan sector type is on trade sector followed by $24.7 \%$ urban agriculture sector type. The Government of Ethiopia wants to transfer these business owners to manufacturing and construction sectors because these sector demands more labor and it is believed that they can help reduce unemployment rate of the region. However, majority of the entrepreneurs planned to work on trade and urban agriculture as these types of sectors demand low initial capital, not so sophisticated skills and technologies and minimum man power as compared to manufacturing and construction type of sectors. Selamawit (2015) showed that majority of entrepreneurs (45\%) were involved on trade sector followed by $26 \%$ of those involved in services sector types.

Table 5. Number of business with long run plan.

\begin{tabular}{|lll|}
\hline Entrepreneurs future plan sector & \multicolumn{2}{l|}{ Response } \\
\cline { 2 - 3 } & N & Percent \\
\hline Urban Agriculture & 60 & $24.7 \%$ \\
\hline Trade & 87 & $35.8 \%$ \\
\hline Service & 27 & $11.1 \%$ \\
\hline Manufacturing & 52 & $21.4 \%$ \\
\hline Construction & 17 & $7.0 \%$ \\
\hline Total & 243 & $100.0 \%$ \\
\hline
\end{tabular}

Most of the entrepreneurs are not willing to transfer to the manufacturing and construction sector types because manufacturing and construction demand more initial capital and labors. Table 6 shows that $60 \%$ of the entrepreneurs were not willing to transfer to manufacturing and (C) CNCS, Mekelle University 
construction due to shortage of capital. $23.5 \%$ and $12.2 \%$ of the entrepreneurs didn't want to transfer due to lack of knowledge on the technologies and its surplus been long time, respectively.

Table 6. Stated or reported constraints on future plan to transfer to manufacturing and construction sectors.

\begin{tabular}{|lll|}
\hline $\begin{array}{l}\text { Constraints on future plan to transfer to manufacturing } \\
\text { and construction sectors }\end{array}$ & Responses \\
\cline { 2 - 3 } & $\boldsymbol{N}$ & Percent \\
\hline Capital Shortage & 143 & $60.1 \%$ \\
\hline It is not profitable & 10 & $4.2 \%$ \\
\hline Doesn't have knowledge & 56 & $23.5 \%$ \\
\hline It's surplus been long time & 29 & $12.2 \%$ \\
\hline Total & 238 & $100.0 \%$ \\
\hline
\end{tabular}

Table 7. Government support to entrepreneurs.

\begin{tabular}{|lcc|}
\hline \multirow{2}{*}{$\begin{array}{l}\text { Nature of government } \\
\text { support }\end{array}$} & \multicolumn{2}{c|}{ Responses } \\
\cline { 2 - 3 } & $\boldsymbol{N}$ & Percent \\
\hline Finance Aspect & 60 & $20.5 \%$ \\
\hline Work shed & 47 & $16.1 \%$ \\
\hline Seller shed & 45 & $15.4 \%$ \\
\hline Market linkage & 32 & $11.0 \%$ \\
\hline Training & 108 & $37.0 \%$ \\
\hline Total & 292 & $100.0 \%$ \\
\hline
\end{tabular}

\subsection{Skills and Capacity Building Acquired from Government/Agency}

According to table 7, 37\% of the entrepreneurs benefitted from training followed by $20.5 \%$ financial access. $16.1 \%, 15.4 \%$ and $11 \%$ of the entrepreneurs benefitted from work sheds; seller shed and market linkage, respectively. The result suggested that the entrepreneurs are constrained by getting market linkage, seller shed and work shed from the government and from the respective MSE agency so as to enrich their performance. Most entrepreneurs start their business with what they have (mostly small initial capital) and from this capital they are expected to pay house rent ahead for a minimum 6 months. The entrepreneurs expect to get sheds but, the government has deficiency of supplying sheds. Therefore, if their initial capital paid ahead for house rents there will be no money left on their saving account for backup and this directly affects performance of the enterprise. Lack of market linkages also present a challenge for the business owners because the sector types are not well integrated with each other and with another partnership. The entrepreneurs and the government have a problem in integrating markets. The market linkage is very important for the entrepreneurs. For one business to perform better one needs market linkage 
through government or partners like bazars and exhibitions in different areas and occasions to promote their work.

Table 8. Training support by MSE agency to entrepreneurs.

\begin{tabular}{|lll|}
\hline Support given by MSE agency & Responses & Percent \\
\hline Technical training & 136 & $35.8 \%$ \\
\hline New technologies & 51 & $13.4 \%$ \\
\hline Kaizen training & 60 & $15.8 \%$ \\
\hline Entrepreneurship training & 50 & $13.2 \%$ \\
\hline Trade management & 83 & $21.8 \%$ \\
\hline Total & 380 & $100.0 \%$ \\
\hline
\end{tabular}

Table 8 indicates that $35.8 \%$ of the entrepreneurs get technical training to improve their skills and performances. $21.8 \%, 15.8 \%, 13.4 \%$ and $13.2 \%$ get support on trade management, kaizen training, new technology and entrepreneurship training, respectively. This result shows that majority of the entrepreneurs got support on technical support and trade management from the government. This result is similar to Zemen and Mohammed (2014) whose result showed that entrepreneurs got more support from government mainly on training (24.21\%) and technology transfer (3.93\%). Apart from the government support, individuals should be aware the technical skills and experience sharing's by participating in different exhibition. The business owners should have their own association to sharing their experiences regularly.

\section{CONCLUSIONS AND RECOMMENDATIONS}

\subsection{Conclusions}

The average age of the business owners was around 40 years old and the average total household size was 3.9. Majority of the business owners education levels were first cycle (grade 1-6) and high Scholl (grade 9-12) and 51\% of the respondents were male headed. $98.37 \%$ of the entrepreneurs their business run by a single person and majority of the entrepreneurs involve on trade $(35.8 \%)$ and urban agriculture $(24.7 \%)$ as these sectors demand low initial capital, not so sophisticated skills and technologies and minimum man power as compared to manufacturing and construction.

The Government of Ethiopia mostly supports on trainings and finance aspects but, limited on market linkage and accessibility of sheds. Majority of the entrepreneurs saved their profit on Dedebit Micro Finance and get credit access from it. Most of the entrepreneurs used their loan for 
work promotion and to expand their existing businesses. The result also revealed that there is gender difference on sector types, work sheds and education level of MSE business owners.

Initial capital is positively related to the performance of MSEs. Most females headed entrepreneurs are involved in less labor intensive economic activities like trade and services sectors. Manufacturing and construction sectors demand more labor/energy and are too mechanical, and females headed entrepreneurs consider these sector enterprises challenging to join. Male headed enterprises perform better than female owned enterprises they are also risk takers. Majority of the entrepreneurs were involved in micro enterprises, because micro enterprise demands low initial capital with almost no additional labor needed than small enterprise. But, entrepreneurs involved in small enterprises better performances, as these enterprises have enough initial capital than micro enterprise. Even if most entrepreneurs prefer to work solely in different sectors due to some challenges, this leads to poor performance of the enterprise. Therefore, business owners should work jointly for better performance of the enterprises.

\subsection{Recommendations}

Based on the major findings mentioned in the analysis, the following recommendations have been drawn with the view to improve the role of MSE in contribution to employment and income generation.

The construction of market sheds and common facility centers at suitable locations by assistance of the Government, donors and private sector could help to address this problem. Thus, government with support from donors could engage in constructing shades for MSEs to address the problem of work place, coupled with measures to encourage private investors to engage in construction of premises suitable for entrepreneurs.

The sector types are not connected with each other and with other trade markets. There are market linkage and technical skill gabs that they seek from government. So the government or the responsible body should create market linkage like bazars or exhibitions to promote their products easily. Peoples start MSE business plan, they should have enough initial capital and it is better to work jointly.

\section{ACKNOWLEDGEMENTS}

We would like to thank for Trans disciplinary Training for Resource Efficiency and Climate Change Adaptation in Africa (TRECCAfrica) scholarship for providing us the budget. 


\section{CONFLICT OF INTERESTS}

There are no conflicts of interest.

\section{REFERENCE}

Aklilu, W. 2010. Analysis of Marketing Practices in Micro and Small Enterprises (MSEs): The Case of Metal and Wood work MSEs in Mekelle City, Tigray, Ethiopia. MSc Thesis, College of Business and Economics, Mekelle University, 86p (unpubl.).

Alasadi, R \& Abdelrahim, A. 2007. Critical analysis and modelling of small business performance (Case Study: Syria). J. Asia Entrepreneurship and sustainability, 3(2): 22p

Amha, W \& Admassie, A. 2004. Development of micro and small enterprises in Ethiopia. Survey report, Ethiopian Development Research Institute, Addis Ababa, 32p.

Araya, A., Keesstra, S.D \& Stroosnijder, L. 2010. A new agro-climatic classification for crop suitability zoning in northern semi-arid Ethiopia. Agric. Forest Meteorol., 151: 1047-1064.

Aregash, A. 2005. Public Private Partnership Projects of the GTZ in Ethiopia. International trade and the protection of natural resources in Ethiopia, Eschoborn, Bonn, Germany. 1-9p.

Bereket Tadesse. 2010. The role of micro and small enterprises in employment creation and income generation: A survey study of Mekelle city, Tigray, Northern Ethiopia. MA Thesis, Department of Management, Mekelle University, 76p.

Bultum, N.D. 2017. Performance of micro and small scale enterprises: the case of Adama, Oromia. World Journal of Economic and Finance, 3(1): 046-051.

Carpenter, C. 2003. SME Finance in Nigeria. Paper presented to the Roundtable on "Making Small Business Finance Profitable in Nigeria”. Accessed at http://www.ypforum.org/newsCarpenter.

Central Statistical Agency (CSA). 2015. Ethiopia Socio-economic Survey 2015-16, Wave 3. Survey ID number ETH_2015_ESS_v03_M, World Bank Group, Addis Ababa, Ethiopia.

Charney, A \& Libecap, G. D. 2000. Impact of entrepreneurship education. Insights: A Kauffman Research Series, Kauffman Center for Entrepreneurial Leadership, Kansas City, pp. 1-8.

Cochran, W.G. 1963. Sampling Techniques, $3^{\text {rd }}$ Edition, Harvard University, ISBN: 978-0-47116240-7, 448p.

Economic Survey. 2009. Kenya National Bureau of Statistics, Nairobi, 330p, available online: http://www.knbs.or.ke 
Egbuogu, 2003. What Small Business Entrepreneurs Expect From Local Credit Agencies and International Business Facilitators. Paper presented at "Business America". A Forum organized by the US Commercial Consulate, Lagos, Nigeria, March 3, pp 1-10.

Ekpeyong, D.B \& Nyong, M.O. 1992. Small and Medium Scale Enterprises in Nigeria: their characteristics, problems and sources of finance. AERC Research Paper 16, African Economic Research Consortium, Nairobi, ISBN 1-897621-09-4, 33p.

FDRE. 2011. Micro and Small Enterprise Development Strategy, provision framework and methods of Implementation, Addis Ababa, Ethiopia.

Gebrehiwot, T \& van der Veen, A. 2013. Assessing the evidence of climate variability in the northern part of Ethiopia. J. Development Agriculture Economics, 5(3): 104-119

Gebreeyesus, M. 2009. Innovation and Microenterprises Growth in Ethiopia. Research Paper No. 2009/51, presented at United Nations University- World Institute for Development Economics Research (UNU-WIDER) and UNU-MERIT Research Workshop on "Entrepreneurship, Technological Innovation, and Development", held in Maastricht, the Netherlands on 30-31 October 2008, paper also published as UNU-MERIT Working Paper 2009-053, ISBN 978-92-9230-230-6, 24p.

Habtamu, T., Aregawi, G \& Nigus, A. 2013. Growth Determinants of micro and Small Enterprises: Evidence from Northern Ethiopia. Journal of Economics and Sustainable Development, 4(9): 128-135.

Hall, G. and Fulshaw, S. 1993. Factors Associated with the Relative Performance amongst Small Firms in the British Instrumentation Sector. In: H. Klandt (ed.) Entrepreneurship and Business Development, pp. 227-237. Aldershot: Avebury.

Hidayet, K., Canan, S., Onur, S \& Hakan, M. K. 2010. The importance of SMEs in Developing Economies. $2^{\text {nd }}$ International Symposium on "Sustainable Development, June 8-9, 2008, Sarajevo, Turkey, pp183-192.

Lussier, R.N. 1995. A nonfinancial business success versus failure prediction model for young firms. Journal of Small Business Management, 33(1), Blackwell Publishers.

Lussier, R. N \& Pfeifer, S. 2001. A cross-national prediction model for business success. Journal of Small Business Management, 39(3): 228-239. 
Mahbub-Ul-Haque Human Development Centre. 2001. Human Development in South Asia 2002: Globalisation and Human Development. ISBN: 0195797647, Oxford University Press 2002, Karachi, xii, 180p.

Mead, D.C \& Liedholm, C. 1998. The dynamics of micro and small enterprises in developing countries. World development, 26(1): 61-74.

MoFED. 2010. Growth and Transformation Plan 2010/11-2014/2015, Addis Ababa, Ethiopia, $85 \mathrm{p}$.

MoFED. 2015. Dynamics of Growth and Poverty Line in Ethiopia.

Wanambisi, A. N \& Bwisa, H. M. 2013. Effects of Microfinance Lending on Business Performance: A Survey of Micro and Small Enterprises in Kitale Municipality, Kenya. International Journal of Academic Research in Business and Social Sciences, 3(7): 56-67 (DOI: 10.6007/IJARBSS/v3-i7/9).

Praag, M. 2003. Business survival and success of young small business owners. Tinbergen Institute Discussion Paper. Available at http.www.tinbergen.in

Rose, R.C., Kumar, N \& Yen, L. L. 2006. The dynamics of entrepreneurs' success factors in influencing venture growth. Journal of Asia Entrepreneurship and Sustainability, 2(3): $19 \mathrm{p}$.

Selamawit, K. 2015. An analysis of micro and small enterprise (MSE) profile (A case of MSE units in Mekelle). Journal of Business Management \& Social Sciences Research, ISSN No: 2319-5614, 4(4). 9p.

Thapa, A., Goswami, T. A \& Joshi, P. 2008. Determinants of street entrepreneurial success. Journal of Nepalese Business Studies, 5(1):8p.

UNDP. 2012. Case studies of sustainable development in practice: triple wins for sustainable development, Design and production by Kimberly Koserowski, First Kiss Creative LLC

USAID, 2010. Federal leadership in environmental energy and economic performance, Washington Dc., 2010

Van Biesebroeck, J. 2005. Firm size matters: Growth and productivity growth in African manufacturing. Economic Development and Cultural Change, 53(3): 545-583.

Walker, E \& Brown, A. 2004. What Success Factors are Important to Small Business Owners? International Small Business Journal, 22(6): 577-594. 
Wanjohi, A.M \& Mugure, A. 2008. Factors affecting the growth of MSEs in rural areas of Kenya: A case of ICT firms in Kiserian Township, Kajiado District of Kenya. MSc Thesis, Entrepreneurship Research Paper, Nairobi. UON Press (Unpubl.).

Zemenu Aynadis and Mohammed Mohammednur 2014. Determinants of growth of micro and small enterprises in Ethiopia (A case of MSEs in mekelle city, Tigray. International Journal of Advance Research in Computer Science and Management Studies, 2(6): 149157. 